Research article

\title{
A new species of Cryptomonas (Cryptophyceae) from the Western Urals (Russia)
}

\author{
Nikita A. MARTYNENKO ${ }^{1, *}$, Evgeniy S. GUSEV ${ }^{2}$, Pavel V. KULIZIN ${ }^{3}$, \\ Elena E. GUSEVA ${ }^{4}$, Kevin McCARTNEY ${ }^{5}$ \& Maxim S. KULIKOVSKIY ${ }^{6}$ \\ 1,2,46 K.A. Timiryazev Institute of Plant Physiology RAS, IPP RAS, 35 Botanicheskaya Street, Moscow, \\ 127276 Russia. \\ ${ }^{3}$ Lobachevsky State University of Nizhniy Novgorod, Gagarina Prosp., 23, 603950 Nizhniy \\ Novgorod, Russia. \\ ${ }^{5}$ University of Maine at Presque Isle, Department of Environmental Science and Sustainability, 181 \\ Main Street, Presque Isle, 04769 U.S.A. \\ *Corresponding author: nikita-martynenko@yandex.ru \\ 2Email: algogus@yandex.ru \\ 32Email: kulizinpavel@yandex.ru \\ ${ }^{4}$ Email: mielenagus@yandex.ru \\ ${ }^{5}$ Email: kevin.mccartney@maine.edu \\ ${ }^{6}$ Email: max-kulikovsky@yandex.ru
}

\begin{abstract}
A new species, Cryptomonas uralensis Martynenko, Gusev, Kulizin \& Guseva sp. nov., is described from western slopes of the Ural Mountains (Russia) based on morphological and molecular data. Phylogenetic relationships inferred from nuclear SSU and LSU rDNA sequences show that the new species forms a clade with $C$. tetrapyrenoidosa Skuja emend. Hoef-Emden \& Melkonian. Comparison of secondary structures of nuclear rDNA ITS2, including analysis of Compensatory Base Changes (CBC), confirms the separation between $C$. uralensis sp. nov. and C. tetrapyrenoidosa. Cell morphology and sizes of $C$. uralensis sp. nov. are very similar to $C$. tetrapyrenoidosa and C. pyrenoidifera, and $C$. uralensis sp. nov. may thus represent a species that can only be reliably identified using molecular data.
\end{abstract}

Keywords. Cryptomonas, new species, SSU rDNA, LSU and ITS2 rDNA markers, nuclear ITS2 secondary structure, Compensatory Base Changes approach, Urals.

Martynenko N.A., Gusev E.S., Kulizin P.V., Guseva E.E., McCartney K. \& Kulikovskiy M.S. 2020. A new species of Cryptomonas (Cryptophyceae) from the Western Urals (Russia). European Journal of Taxonomy 649: 1-12. https://doi.org/10.5852/ejt.2020.649

\section{Introduction}

Cryptophytes (also known as cryptomonads) are mostly photoautotrophic, unicellular, biflagellate, softbodied protists distributed in diverse freshwater, brackish, and marine habitats. They are characterized by a number of morphological and ultrastructural features, including a distinct cellular asymmetry, presence of extrusive organelles (termed ejectosomes), cell-covering from organic compounds (termed 
periplast), and a remnant nucleus of endosymbiotic origin in close association with the plastids (HoefEmden \& Archibald 2016).

Recent research has shown that even in well-sampled geographical regions and habitats, the true diversity of cryptomonads is often unknown (Hoef-Emden 2007; Lane \& Archibald 2008; Shalchian-Tabrizi et al. 2008; Choi et al. 2013). Cryptomonas Ehrenb. (Ehrenberg 1831) is a diverse genus of cryptophytes, with about 70 morphospecies currently accepted (Hoef-Emden \& Melkonian 2003). Species in the genus are restricted to freshwater, contain chloroplasts with the biliprotein phycoerythrin 566 or leucoplasts, and are characterized by a dimorphic life cycle (Hoef-Emden \& Melkonian 2003). Species display two alternative cell morphotypes, which are related to the life cycle: 1) cryptomorph with an inner periplast composed of hexagonal to polygonal organic plates and a non-keeled posteriorly directed microtubular flagellar root, and 2) campylomorph with a sheet-like inner organic periplast component and keeled rhizostyle (Hill 1991; Hoef-Emden \& Melkonian 2003).

Molecular phylogenetic analyses based on nuclear and nucleomorph ribosomal RNA gene sequences demonstrated inconsistencies with traditional Cryptomonas taxonomy based on cell morphology studies by light microscopy (LM). Hoef-Emden \& Melkonian (2003) revised the genus by combining phylogenetic analyses with morphological data, emended several species by including molecular data, and described two new species. DNA sequences of additional strains resulted in emendation of five species including one new combination (Hoef-Emden 2007). Identification of most Cryptomonas species may be possible only with molecular data. A total of 14 Cryptomonas species can now be identified by nuclear ITS2/partial LSU rDNA or by nucleomorph SSU rDNA sequences in molecular ecological surveys (Hoef-Emden \& Melkonian 2003; Hoef-Emden 2007). It is worth mentioning that these taxa are phylogenetic species, which may not correspond to biological species limits.

Cryptomonads from some freshwater habitats in Russia have been studied morphologically, but molecular data is currently lacking. Data on taxonomic composition and ecology of this group are available mainly from phytoplankton studies. Cryptomonas marssonii Skuja, C. ovata Ehrenb. and C. erosa Ehrenb. have been reported from the Urals based on morphological data (Tretyakova et al. 1988; Tretyakova

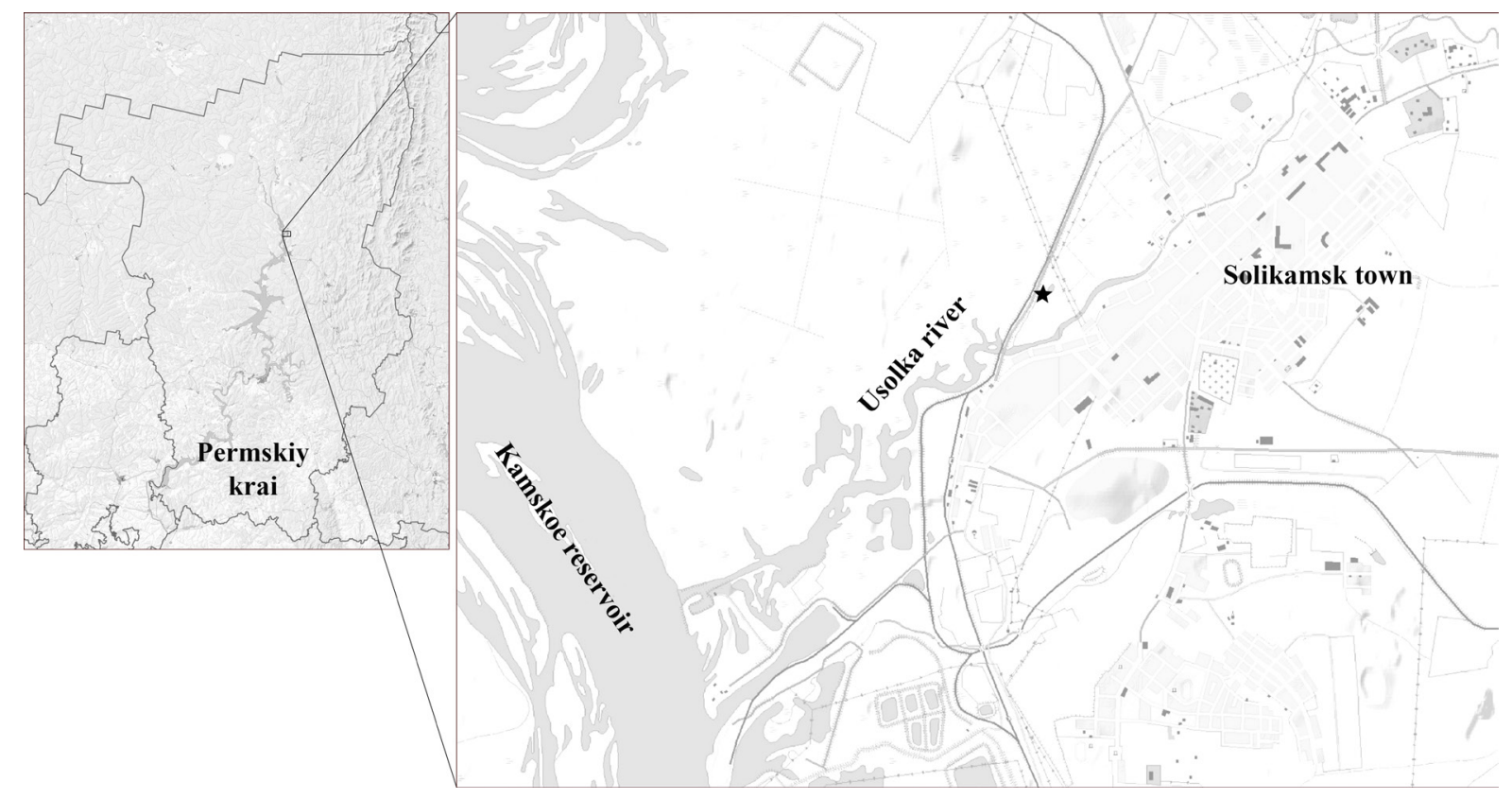

Fig. 1. Map of the study area; created using SASPlanet (http://www.sasgis.org). 
1989; Belyaeva 2013, 2015). A new species of Cryptomonas from Russia is here described based on combination of morphological and molecular data.

\section{Material and methods}

\section{Study area}

Samples were collected from an unnamed small lake in the Usolka River flood plain, located in

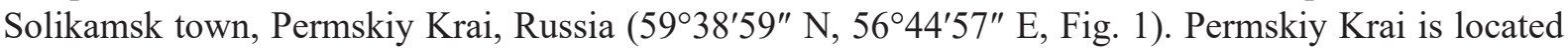
on the western slope of the Ural Mountains, in upper and middle reaches of Kama River basin. The climate is cold temperate, with an average January temperature of $-18.9^{\circ} \mathrm{C}$, and varies from $+14.8^{\circ} \mathrm{C}$ in the north to $+18.7^{\circ} \mathrm{C}$ in the south during July. The annual precipitation also varies, from $450-600 \mathrm{~mm}$ in the western plain to $700-1000 \mathrm{~mm}$ in eastern mountainous territories of the Northern Urals, with snow cover usually 160-170 days/year (Nazarov 2006).

\section{Samples and collections}

Planktonic samples were collected by the first author using a plankton net with $20 \mu \mathrm{m}$ mesh size. Water mineralization and temperature measurements were performed using the Hanna device (HI 9828, Hanna Instruments, Inc., Woonsocket, RI, USA). Strains were isolated and cultures perpetually transferred to IPPAS (Culture Collection of Microalgae at the K.A. Timiryazev Institute of Plant Physiology of the Russian Academy of Sciences).

\section{Culturing}

Monoclonal strains were established by examination of micropipetted single cells under an inverted microscope. Non-axenic unialgal cultures were maintained in WC and Waris-H liquid medium (Andersen 2005; McFadden \& Melkonian 1986) at $10^{\circ} \mathrm{C}$ in a growth chamber with a $12: 12 \mathrm{~h}$ light:dark photoperiod.

\section{Light microscopy}

For light microscopy, living cells were immobilized by embedment in ultra-low gelling agarose (SigmaAldrich, A4018, USA) and examined by Nomarski differential interference contrast (DIC) with an oil immersion lens (Plan-Apochromat 100x/1.40 Oil DIC M27; microscope Zeiss AxioScope A1; Carl Zeiss AG, Oberkochem, Germany). Cell shape, size, shape of the furrow-gullet system and cell plastids, and presence, number and position of pyrenoids were examined ( 88 cells). The morphological description follows the nomenclature of Hoef-Emden \& Melkonian (2003) (ventral side corresponds to the opening side of the furrow-gullet system). Calibration of magnification was done with a grated micrometer. Light micrographs were taken with an AxioCam ERc 5s Rev.2.

\section{DNA extraction and amplification}

Total DNA was extracted from monoclonal cultures using InstaGeneTM Matrix according to manufacturer's protocol. Fragments of SSU (length $1533 \mathrm{bp}$ ) and LSU rDNA (length $946 \mathrm{bp}$ ) and ITS2 rDNA (402 bp) were amplified using primers from Choi et al. (2013): 18S_CrN1F, 18S_826F, 18S_956R, 18S_BRK for nuclear SSU rDNA, crLSU_29F and crLSU_942R for partial nuclear LSU rDNA, and crITS_03F and crITS_05R for nuclear ITS2 rDNA. Amplification of all studied fragments was carried out using the premade mix ScreenMix (Evrogen, Russia) for the polymerase chain reaction (PCR). The conditions of amplification for SSU rDNA, LSU rDNA and ITS2 rDNA fragments were: an initial denaturation of $5 \mathrm{~min}$ at $95^{\circ} \mathrm{C}$, followed by 35 cycles at $94^{\circ} \mathrm{C}$ for denaturation $(30 \mathrm{~s}), 52^{\circ} \mathrm{C}$ for annealing $(30 \mathrm{~s})$ and $72^{\circ} \mathrm{C}$ for extension $(50-80 \mathrm{~s})$, and a final extension step of $10 \mathrm{~min}$ at $72^{\circ} \mathrm{C}$. The resulting amplicons were visualized by horizontal agarose gel electrophoresis (1.5\%), colored with SYBR Safe (Life Technologies, Carlsbad, CA, USA). Purification of DNA fragments was performed 
with the ExoSAP-IT kit (Affymetrix, Santa Clara, CA, USA) according to manufacturer's protocol. SSU rDNA, LSU rDNA and ITS2 rDNA fragments were decoded from two sides using forward and reverse PCR primers and the Big Dye system (Applied Biosystems, Foster City, CA, USA), followed by electrophoresis using a Genetic Analyzer 3500 sequencer (Applied Biosystems, Foster City, CA, USA).

\section{Phylogenetic analysis}

Electropherograms were verified by eye and sequences were assembled using BioEdit ver. 7.1.3 and MegaX (Kumar et al. 2018). Newly determined sequences and GenBank sequences of 45 other cryptomonads from different morphological groups were included in the alignments. The species Rhodomonas sp. strain M1480 and Chroomonas sp. strain SAG 980-1 were chosen as outgroup taxa. Sequences were aligned using MAFFT ver. 7 with model EINS-i (Katoh \& Toh 2010), refined by eye and difficult to align regions were excluded from the analysis. jModelTest ver. 2.1.1 indicated that the GTR model of nucleotide substitution, with Gamma (G) distributed rates across sites and a proportion of invariable sites (I), was the most appropriate evolutionary model for the SSU rDNA and LSU rDNA alignments separately and combined (Posada 2006). Finally, we constructed the concatenated SSU + LSU rDNA alignment of 47 taxa. The SSU and LSU sequences were combined from the same strain. Phylogenies were constructed based on this model for the concatenated alignment using a single partition Bayesian Inference (BI) and Maximum Likelihood (ML) analyses. BI analysis was conducted with MrBayes ver. 3.2.5 (Ronquist \& Huelsenbeck 2003). Three "hot" and one "cold" Markov chains were run for $1 \times 10^{6}$ cycles in two repetitions with the selection of each $200^{\text {th }}$ generated tree. Phylogenetic tree and posterior probabilities were obtained after discarding the first $25 \%$ to produce estimate parameter models of nucleotide substitutions and likelihood. ML-analysis was performed using MegaX (Kumar et al. 2018). Branch support was estimated using bootstrap analysis with 1000 replicas. Viewing and editing of trees were performed in FigTree ver. 1.4.2 (FigTree 2014) and Adobe Photoshop CC (ver. 19.0).

\section{RNA secondary structure prediction}

Nuclear ITS2 sequences were folded using the mfold server (http://mfold.rna.albany.edu/?q=mfold/RNA-Folding-Form) (Zuker 2003) with default values. HoefEmden (2007) provided a complete RNA secondary structure graph of the nuclear ITS2 rDNA of Cryptomonas sp. M1634, which was used as a template and assisted in inference of common stems, loops, and bulges.

\section{Results}

\section{Molecular phylogeny}

The new species, Cryptomonas uralensis sp. nov., represents a separate clade with high statistical support, sister to Cryptomonas tetrapyrenoidosa Skuja emend. Hoef-Emden \& Melkonian (Fig. 13). Cryptomonas uralensis sp. nov. differs from the type strain of $C$. tetrapyrenoidosa by the SSU rDNA, LSU rDNA and ITS2 rDNA sequences as well as in the secondary structure of ITS2 (Fig. 14). For ITS2 sequence of $C$. uralensis sp. nov. four-helix structures could be inferred with long third helices (Fig. 15). An unpaired U-U was found in Helix II. The length of the helices was different between two taxa (Fig. 15). For the new species, length of ITS2 was 402 nt, while for C. tetrapyrenoidosa was $370 \mathrm{nt}$. Three Compensatory Base Changes (CBCs) between C. uralensis sp. nov. and C. tetrapyrenoidosa were observed in Helix III (Fig. 15). 


\section{Phylum Cryptophyta Cavalier-Smith \\ Class Cryptophyceae F.E.Fritsch \\ Order Cryptomonadales Pascher \\ Genus Cryptomonas Ehrenb.}

Cryptomonas uralensis Martynenko, Gusev, Kulizin \& Guseva sp. nov.

Figs $2-12$

\section{Diagnosis}

Cells (absolute minimal and maximal values of strain UR168) 15-26 $\mu \mathrm{m}$ long, $8-17 \mu \mathrm{m}$ wide, $8-12 \mu \mathrm{m}$ thick. Cells more or less flattened in dorso-ventral plane, in ventral view elliptical to ovoid. In lateral view with oblique or rounded apex and rounded antapex. One plastid with two to four pyrenoids. Species differs from other species of the genus by the order of nucleotides in nuclear ITS2, LSU and SSU rDNA gene sequences.

\section{Etymology}

The species name derived from "Ural", the region from which this taxon was described.

\section{Type material}

\section{Holotype}

RUSSIA • Solikamsk town, water-body in the Usolka River flood plain; 59 $38^{\prime} 59^{\prime \prime}$ N, 56 44'57" E; 2014; collected by N.A. Martynenko; strain UR168; GenBank MN509781, MN509779; MHA[Cryptomonas uralensis Russia Martynenko 20-2 MHA, strain UR168].

The holotype is a large drop of unfixed dried cells of the strain UR168 (=IPPAS H-2046) on water colour paper (hic designatus), deposited at MHA (Herbarium, Main Botanical Garden, Botanicheskaya Str. 4, Moscow, 127276, Russia) under the designation Cryptomonas uralensis Russia Martynenko 20-2 MHA, strain UR168. Representative living strain and DNA sample are kept at IPPAS.

\section{Representative DNA sequences}

GenBank accession numbers MN509781 (nuclear ITS2 and partial nuclear LSU rDNA), and MN509779 (nuclear SSU rDNA).

\section{Authentic strain}

UR168 (=IPPAS H-2046).

\section{Type locality}

A water-body in the Usolka River flood plain, Solikamsk town, Russia. Latitude/Longitude $59^{\circ} 38^{\prime} 59^{\prime \prime} \mathrm{N}$, 56 $6^{\circ} 44^{\prime} 57^{\prime \prime}$ E, collected by N.A. Martynenko in 2014.

\section{Other representative culture}

UR167, GenBank accession numbers MN509780 (nuclear ITS2 and partial nuclear LSU rDNA), and MN509778 (nuclear SSU rDNA).

\section{Geographical distribution}

To date, Cryptomonas uralensis sp. nov. has only been observed at the type locality. At the time of collection, the $\mathrm{pH}$ was 6.5 , temperature $18^{\circ} \mathrm{C}$. 

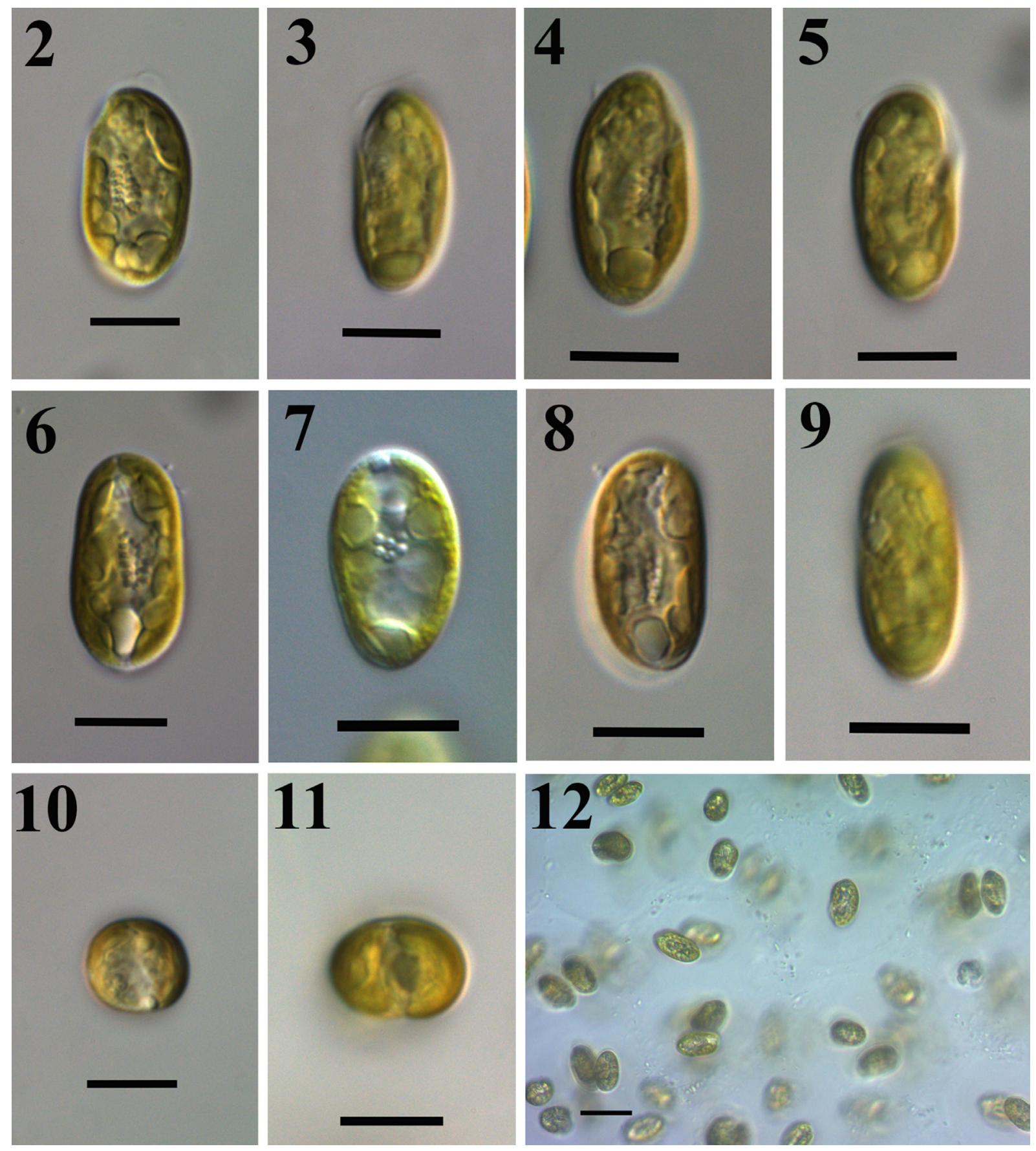

Figs 2-12. Light micrographs of Cryptomonas uralensis Martynenko, Gusev, Kulizin \& Guseva sp. nov. (strain UR168). 2-3. Lateral view (left side). 4-5. Lateral view (right side). 6-8. Ventral view. 9. Dorsal view. 10-11. Apical view. 12. Cells of the strain UR168 in mucilage. Scale bars: $10 \mu \mathrm{m}$. 


\section{Discussion}

Cryptomonas uralensis sp. nov. represents a distinct clade with high statistical support, sister to C. tetrapyrenoidosa, but no obvious morphological characters distinguishing the two taxa were found. Initially C. tetrapyrenoidosa was described based on LM studies of populations from Sweden and Latvia (Skuja 1948). Later, the strain M1092 from Germany (Remscheid) was chosen as the epitype and sequenced (Hoef-Emden \& Melkonian 2003). To date, C. tetrapyrenoidosa has not been recorded in the Urals, thus areals of this species and C. uralensis sp. nov. do not overlap. Mention should be made that there were no previous intensive molecular studies of cryptophytes in the Urals. Recent studies of cryptomonads of South Korea, region remote from Europe, revealed several strains from the Cryptomonas tetrapyrenoidosa clade that showed SSU rDNA, LSU rDNA and ITS2 rDNA nucleotide differences from the type specimen and formed two subclades (Choi et al. 2013). However, no formal taxonomic descriptions have been made. In our opinion, these are very likely a new species. Thus, the C. tetrapyrenoidosa clade requires further study.

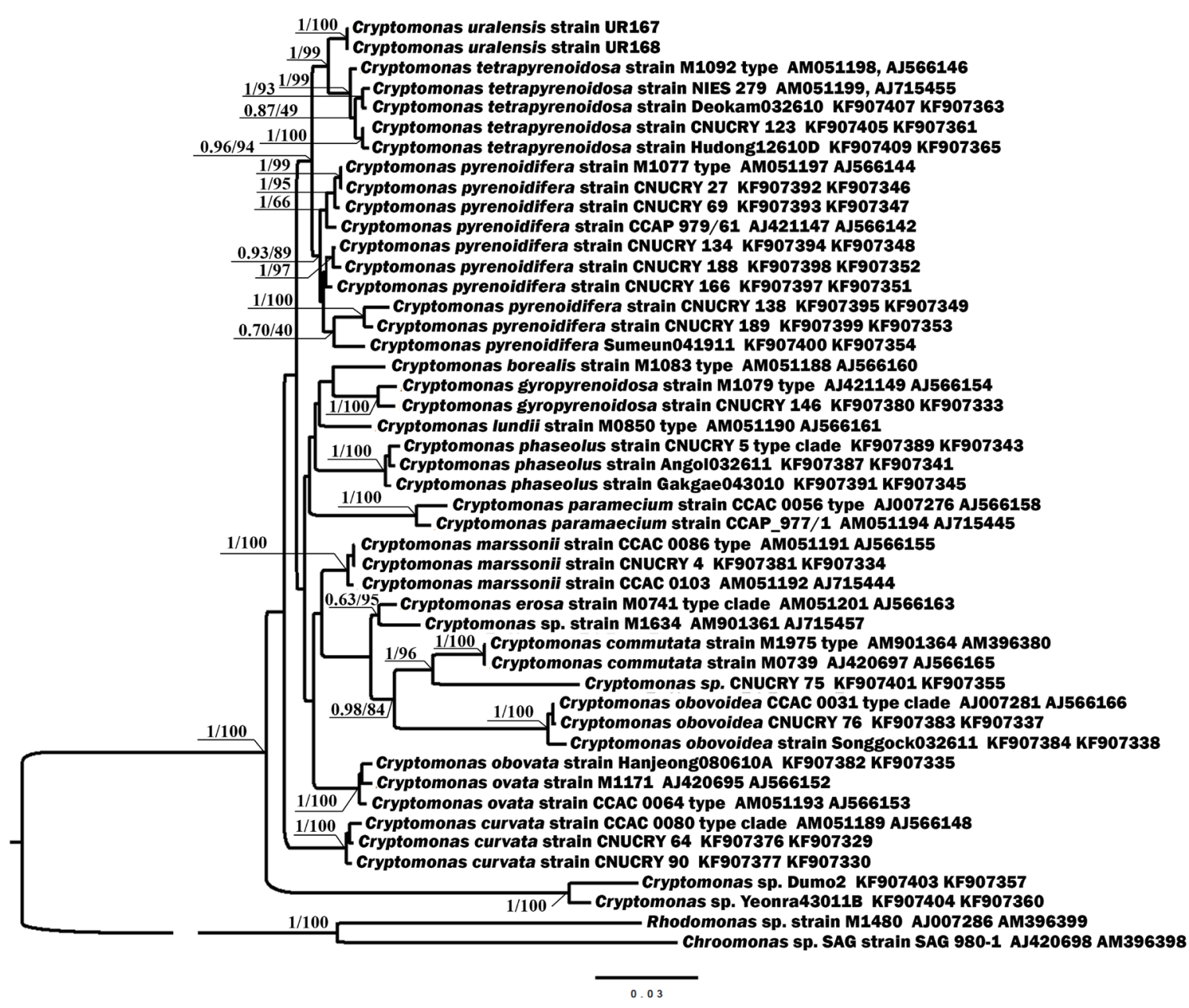

Fig. 13. Bayesian phylogenetic tree of the partial small subunit rDNA (SSU rDNA) and large subunit ribosomal DNA (LSU rDNA) combined data set. The Bayesian posterior probability (left) and maximum likelihood bootstrap value (right) are shown. Scale bar represents estimated number of substitution per site. 
Previous studies have suggested that the nuclear internal transcribed spacer 2 (ITS2) is a good marker to identify biological species using degree of conservation. Coleman (2000) and Müller et al. (2007) have proposed that CBCs in the ITS2 correlate with speciation and thus can be used to distinguish species. The CBC species concept states that two organisms/strains whose ITS2 sequences differ by even a single $\mathrm{CBC}$ in the conserved regions of Helix II and Helix III represent two different biological species (Coleman 2000). According to Müller et al. (2007) and Wolf et al. (2013) the presence of any CBC in the whole ITS2 molecule is sufficient for distinguishing species. Later, Caisová et al. (2013) identified consensus structure model of the ITS2 molecule that can be applied to two classes of green algae. Also was reported that CBCs in the ITS2 of four orders of the green algal class Chlorophyceae Wille in Warming were mostly associated with higher order taxonomic levels like genera, families and orders, and $\mathrm{CBC}$ concept for species delimitation have some constraints in chlorophycean algae (Caisová et al. 2013). Dimorphic strains and a few reports of sexual reproduction indicate the presence of biological species also in cryptophyte taxa (Hoef-Emden 2007). The nuclear ITS2 was successfully used to predict putative biological species in the last revision of Cryptomonas (Hoef-Emden 2007). Here, comparison of the secondary structures of ITS2 confirms separation between $C$. uralensis sp. nov. and C. tetrapyrenoidosa.

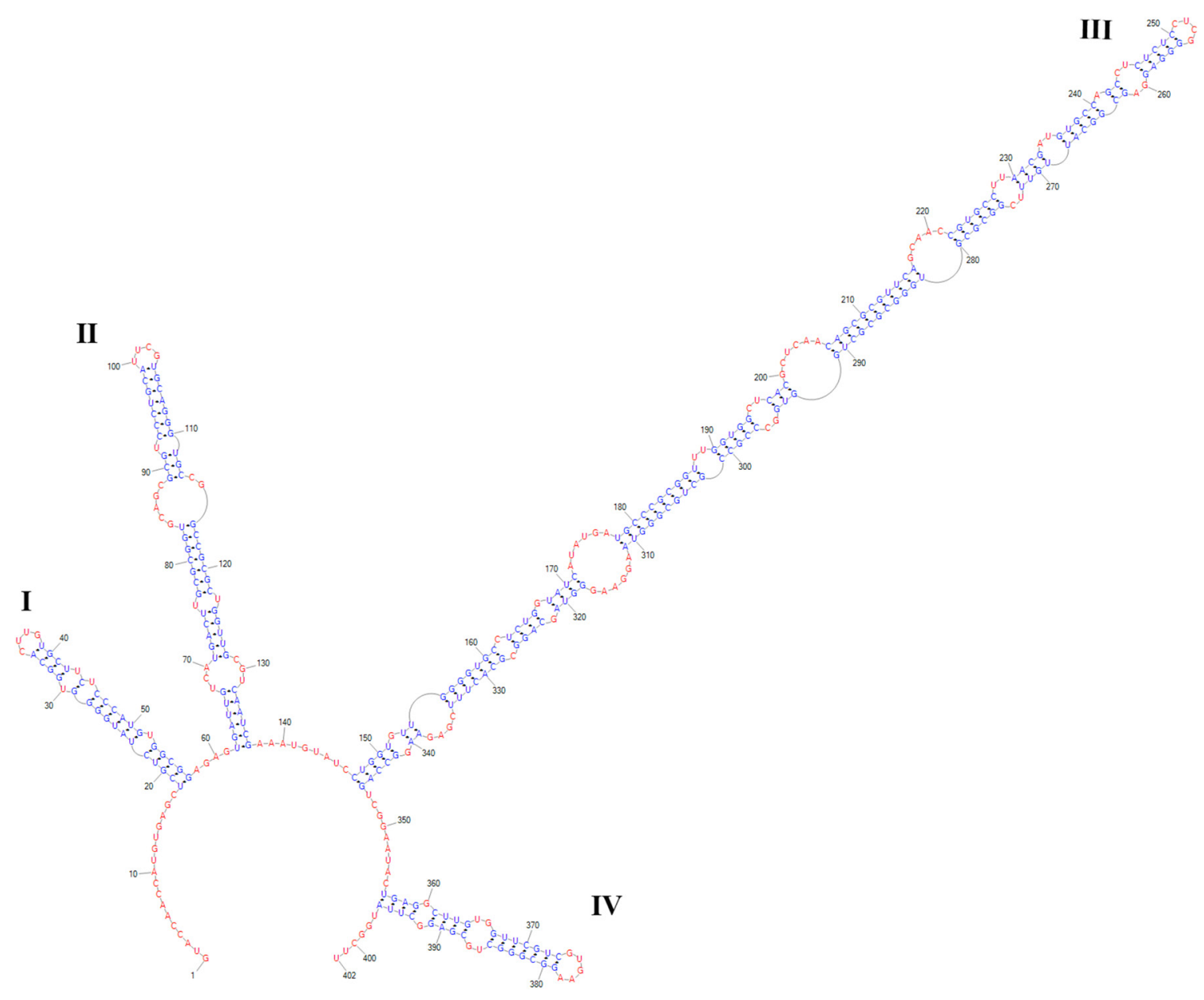

Fig. 14. Predicted secondary structure of the nuclear internal transcribed spacer 2 of the strain UR168 (from 5' to 3' terminus in clockwise direction). 


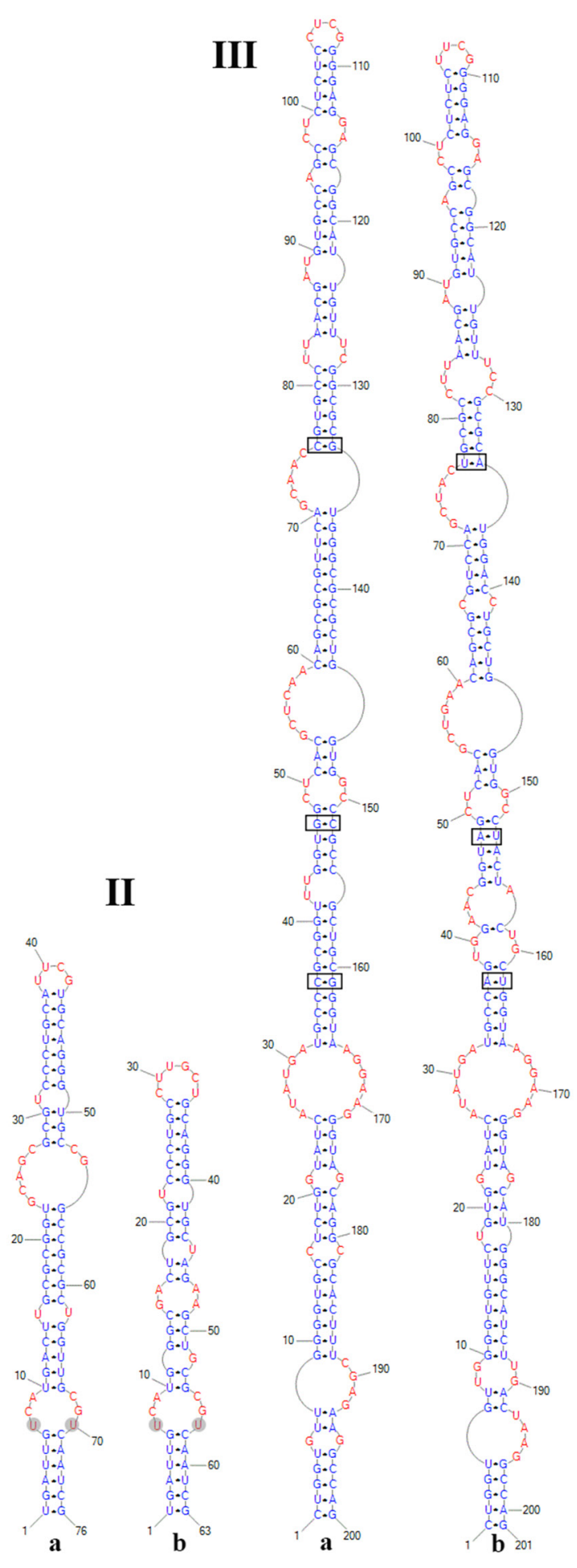

Fig. 15. Predicted secondary structures of the nuclear internal transcribed spacer 2 helix II and helix III (clockwise from 5' to 3' termini) of Cryptomonas uralensis Martynenko, Gusev, Kulizin \& Guseva sp. nov. (a, strain UR168) and C. tetrapyrenoidosa Skuja emend. Hoef-Emden \& Melkonian (b, strain M1092, GenBank accession number AJ566146). CBCs are marked by rectangular boxes. In both helices II, the conserved unpaired U-U motif was found. 
Cryptomonas pyrenoidifera Geitler emend. Hoef-Emden \& Melkonian was found to be sister to the clade containing C. uralensis sp. nov. and C. tetrapyrenoidosa. Cryptomonas pyrenoidifera is known from Germany, United Kingdom, Czech Republic and Australia based on molecular data. The morphology and cell sizes of $C$. uralensis sp. nov. are very similar to cryptomorphs of $C$. pyrenoidifera, as well as C. tetrapyrenoidosa. Cryptomonas curvata Ehrenberg emend. Hoef-Emden \& Melkonian is one more species which has cryptomorph cells with the same morphological features (shape, size, number of pyrenoids), but placed distantly on phylogenetic tree from C. uralensis sp. nov. Incongruences between classical morphospecies and molecular phylogenetic trees have previously been reported for many species in the genus Cryptomonas (Hoef-Emden 2007). Morphological species descriptions of this genus are often ambiguous because of microscopic cells and only few visible characters. The most recent revisions of the genus show that correct identification of most Cryptomonas species may be possible only with molecular data (Hoef-Emden \& Melkonian 2003, Hoef-Emden 2007). In the case of C. uralensis sp. nov., no sufficiently distinct morphological characters could be identified. The species can only be distinguished by molecular characters.

\section{Acknowledgements}

Authors are grateful to D. Kapustin for help in preparation of two images (Figs 7 and 12) and I. Pozdeev for collection assistance. Authors are grateful for reviewers for constructive comments which help to improve the manuscript. This study was supported by RFBR grant $\mathrm{N}^{\circ} 18-04-01280$ a and a framework of the state assignment (theme AAAA-A19-119041190086-6).

\section{References}

Andersen R.A. (ed.) 2005. Algal Culturing Techniques. Elsevier Academic Press, Oxford.

Belyaeva P.G. 2013. Species composition and phytoplankton structure of the Kama reservoir. Bulletin of Perm University. Series: Biology 3: 4-12.

Belyaeva P.G. 2015. Spatio-temporal changes in the phytoplankton of the Kama reservoir Bulletin of the Samara Scientific Center of the Russian Academy of Sciences 17: 733-738.

Caisová L., Marin B., Melkonian M. 2013. A consensus secondary structure of ITS2 in the Chlorophyta identified by phylogenetic reconstruction. Protist 164: 482-496. https://doi.org/10.1016/j.protis.2013.04.005

Choi B., Son M., Jong Im Kim J.I. \& Shin W. 2013. Taxonomy and phylogeny of the genus Cryptomonas (Cryptophyceae, Cryptophyta) from Korea. Algae 28: 307-330.

https://doi.org/10.4490/algae.2013.28.4.307

Coleman A.W. 2000. The significance of a coincidence between evolutionary landmarks found in mating affinity and a DNA sequence. Protist 151: 1-9. https://doi.org/10.1078/1434-4610-00002

Ehrenberg C.G. 1831. Symbolae physicae seu icones et descriptiones animalium evertebratorum sepositis insectis quae ex itinere per Africanum Borealem et Asiam Occidentalem Friderici Guilelmi Hemprich et Christiani Godofredi Ehrenberg medicinae et chirurgiae doctorum studio novae aut illustratae redierunt. Berlin, Mittler.

FigTree 2014. FigTree version 1.3.2. Available from http://tree.bio.ed.ac.uk/software/figtree/ [accessed 20 Apr. 2020].

Hill D.R.A. 1991. A revised circumscription of Cryptomonas (Cryptophyceae) based on examinations of Australian strains. Phycologia 30 (2): 170-188. https://doi.org/10.2216/i0031-8884-30-2-170.1 
Hoef-Emden K. 2007. Revision of the genus Cryptomonas (Cryptophyceae) II: Incongruences between classical morphospecies concept and molecular phylogeny in smaller pyrenoid-less cells. Phycologia 46 (4): 402-428.

Hoef-Emden K. \& Archibald J.M. 2016. Cryptophyta (Cryptomonads). In: Archibald J.M., Simpson A.G.B., Slamovits C.H., Margulis L., Melkonian M., Chapman D.J. \& Corliss J.O. (eds) Handbook of the Protists. Springer International Publishing, Cham, Switzerland.

https://doi.org/10.1007/978-3-319-28149-0_35

Hoef-Emden K. \& Melkonian M. 2003. Revision of the genus Cryptomonas (Cryptophyceae): A combination of molecular phylogeny and morphology provides insights into a long-hidden dimorphism. Protist 154: 371-409. https://doi.org/10.1078/143446103322454130

Katoh K. \& Toh H. 2010. Parallelization of the MAFFT multiple sequence alignment program. Bioinformatics 26: 1899-1900. https://doi.org/10.1093/bioinformatics/btq224

Kumar S., Stecher G., Li M., Knyaz C. \& Tamura K. 2018. MEGA X: Molecular Evolutionary Genetics Analysis across computing platforms. Molecular Biology and Evolution 35: 1547-1549. https://doi.org/10.1093/molbev/msy096

Lane C.E. \& Archibald J.M. 2008. New marine members of the genus Hemiselmis (Cryptomonadales, Cryptophyceae). Journal of Phycology 44 (2): 439-450.

https://doi.org/10.1111/j.1529-8817.2008.00486.x

McFadden G.I. \& Melkonian M. 1986. Use of Hepes buffer for microalgal culture media and fixation for electron microscopy. Phycologia 25: 551-557. https://doi.org/10.2216/i0031-8884-25-4-551.1

Müller T., Philippi N., Dandekar T., Schultz J. \& Wolf M. 2007. Distinguishing species. RNA 13: 14691472. https://doi.org/10.1261/rna.617107

Nazarov N.N. 2006. Geography of the Perm region. Part I. Natural (physical) geography. Publishing House of Perm State University, Perm.

Posada D. 2006. Modeltest Server: a web-based tool for the statistical selection of models of nucleotide substitution online. Nucleic Acids Research 34: 700-703. https://doi.org/10.1093/nar/gk1042

Ronquist F. \& Huelsenbeck J.P. 2003. MrBayes 3: Bayesian phylogenetic inference under mixed models. Bioinformatics 19: 1572-1574. https://doi.org/10.1093/bioinformatics/btg180

Shalchian-Tabrizi K., Brate J., Logares R., Klaveness D., Berney C. \& Jakobsen K.S. 2008. Diversification of unicellular eukaryotes: Cryptomonad colonizations of marine and fresh waters inferred from revised 18S rRNA phylogeny. Environmental Microbiology 10 (10): 2635-2644. https://doi.org/10.1111/j.1462-2920.2008.01685.x

Skuja H. 1948. Taxonomie des Phytoplanktons einiger Seen in Uppland, Schweden. Symbolae Botanicae Upsaliensis 9 (1): 1-399.

Tretyakova S.A. 1989. Phytoplankton of the Kama reservoirs. In: Yarushina M.I. (ed.) Hydrobiological characteristics of the Urals. Ural Branch of USSR Academy of Sciences, Sverdlovsk.

Tretyakova S.A., Golovacheva S.I. \& Batova E.M. 1988. Phytoplankton. In: Aleksevnina M.S. (ed.) Biology of the Votkinsk reservoir. Publishing of Irkutsk University, Irkutsk.

Wolf M., Chen S., Song J., Ankenbrand M. \& Müller T. 2013. Compensatory Base Changes in ITS2 Secondary Structures Correlate with the Biological Species Concept Despite Intragenomic Variability in ITS2 Sequences - A Proof of Concept. PLoS ONE 8: e66726.

https://doi.org/10.1371/journal.pone.0066726 
Zuker M. 2003. Mfold web server for nucleic acid folding and hybridization prediction. Nucleic Acids Research 31: 3406-3415. https://doi.org/10.1093/nar/gkg595

Manuscript received: 26 September 2019

Manuscript accepted: 26 February 2020

Published on: 20 May 2020

Topic editor:Frederik Leliaert

Desk editor: Natacha Beau

Printed versions of all papers are also deposited in the libraries of the institutes that are members of the EJT consortium: Muséum national d'histoire naturelle, Paris, France; Meise Botanic Garden, Belgium; Royal Museum for Central Africa, Tervuren, Belgium; Royal Belgian Institute of Natural Sciences, Brussels, Belgium; Natural History Museum of Denmark, Copenhagen, Denmark; Naturalis Biodiversity Center, Leiden, the Netherlands; Museo Nacional de Ciencias Naturales-CSIC, Madrid, Spain; Real Jardín Botánico de Madrid CSIC, Spain; Zoological Research Museum Alexander Koenig, Bonn, Germany; National Museum, Prague, Czech Republic. 